\title{
Misinformation: Understanding the Evolution of Deception
}

\author{
Silvia Covacio \\ University of South Australia, Adelaide, Australia
}

\section{Silvia.Covacio@unisa.edu.au}

\begin{abstract}
The ensuing discussion of the evolutionary principles surrounding misinformation describes how misinformation creates similar mindsets and behaviour patterns. The evolutionary process of misinformation is often a battle of opposing entities or forces - the rhythm of domination and subservience, altruism and egoism. For misinformation to succeed it requires all interrelated actors to remain, inadvertently or voluntarily, silent and cooperative with the misinformation sender. The negativity breeds negativity, which creates an unstable organisational environment leading to the collapse of the system supported on a misinformation foundation.

Many organisations are based on this rhythm, and Michel Foucault affirms that organisations are repressive systems that require misinformation to control and dominate through knowledge management. The dominating organisational forces often include the use of unethical practices utilizing misinformation to dominate individuals, committees, other organisations, and the market.

The hope of survival lies in the rise of Comte's altruistic and ethical behaviour patterns beginning on an individual level, spreading within the unethical organisation to related organisations, and governments.
\end{abstract}

Keywords : power, control, selfishness, altruism, ethics

\section{Introduction}

\section{“O, what a tangled web we weave, when first we practice to deceive.” Sir Walter Scott}

Deliberate misinformation or disinformation is a psychological control tactic requiring the sender to devise stories containing a mixture of fact and fantasy that are distributed as 'information' to a selected audience by the most appropriate communication channels. It is probable the evolutionary process develops when an innocent, individual, young neophyte utilizes this tactic to ensure others do not have control of often playful or mischievous situations. When the neophyte recognizes the short-term value of the tactic, the continued assurance of power and control over others can take a stronghold and extend into adulthood. The actions and attitude develop into a habitual practice of an older adult wielding autocratic control over family, partners, staff, or other organizations, unless of course, another stronger, wiser, and cunning individual defeats, on a repeated basis, the autocratic individual. This is Darwinian process of natural selection or as Darwin suggests, Spencer's terminology of "survival of the fittest" (cited in Darwin, 1958 p.75) coming into play.

Material published as part of these proceedings, either on-line or in print, is copyrighted by Informing Science. Permission to make digital or paper copy of part or all of these works for personal or classroom use is granted without fee provided that the copies are not made or distributed for profit or commercial advantage AND that copies 1) bear this notice in full and 2) give the full citation on the first page. It is permissible to abstract these works so long as credit is given. To copy in all other cases or to republish or to post on a server or to redistribute to lists requires specfic permission from the publisher at Publisher@InformingScience.org
Darwin discusses natural selection from a biological perspective, whereas misinformation begins with thought processes leading to action. No deliberate action happens unless a selection process of ideas has occurred within the individual. The synchronization of mental and physical functions relates to the evolution of ideas, or the survival of the fittest ideas, identified as the Theory of Me- 
metics, discussed by Dawkins (1989), and Blackmore (1999). The theory of memetics therefore can be applied to understanding the evolution of misinformation or deception. Deception is an idea with its roots in trickery, fraudulence, double-dealing, insincerity, and artifice, and if deceitfulness is to survive it must battle against opposing forces of honesty, fairness, sincerity, and openness. Misinformation will try and outwit the opposing forces but opposing forces also follow the same survival techniques and the survival of the fittest depends on the choices of individuals, who may connect, amass, and counterattack. Whether those choices are positive or negative depend on the individual mindset which aligns each individual into the most appropriate camp. Misinformation can propagate using further misinformation, or truthfulness in regard to the use of misinformation, whereas honesty can not survive if misinformation is utilized to propagate honesty.

The deliberate use of misinformation is powerfully ingrained in society to the extent that specific go vernment agencies are constructed upon misinformation strategies. Intelligence agencies use misinformation to discover secrets, confuse counter-intelligence services, to create political unrest or scandal, and to hide information discovered from rivals (Millet, 1994). Espionage and covert activities are games of lies and double-lies and undercover warfare is based on the expertise of operatives to convincingly deceive and withstand this style of psychological warfare. Sandow-Quirk (2002) indicates governments are not the only organisations to exploit misinformation. The intensification of competition is forcing many businesses and criminals to utilise misinformation to gain a short-term competitive advantage.

For misinformation to be accepted by recipients, it must agree with the recipient's current cognitive patterns, which may entail individual or group surveillance. In some situations, a continual feed of misinformation for total message acceptance over a period of time is required. This depends on the content of the message, the amount of misinformation, the audience, and the impetus. Although this type of situation appears complicated, it is plausible, but requires three steps for success: firstly, understanding any previous misinformation transmissions; secondly, delivery of a convincing deception that matches the recipient's current mindset; and finally, devotion to message delivery. The importance of misinformation effectiveness involves being aware of counter-misinformation from other sources, and ensuring the same source remains vigilant of all outgoing messages guaranteeing successful message deployment and acceptance.

Misinformation is often applied to dominate or control situations to ensure submission or subjugation. This is often the case in abusive situations where the dominator is undesirous of external interference. Misinformation also means knowledge is limited or lessened, which can diminish the magnitude of power and control, and may also misdirect or deflect power and control. Both situations are used to mollify the audience into a false sense of security or it can be used to create selected emotional situations for other agendas to be instigated. Deliberate misinformation to change the direction of a threatening individual, thwart a large-scale enemy attack, distil power, control and knowledge in society, or increase the perceived power of an individual, group or nation, has been described and in mythology and ancient religions. The explanation of misinformation usage also extends into ancient and modern political and military scenarios, academic research, and space exploration.

What if the recipient detects the misinformation? Justification for the lie can include various cover-ups, for example, further misinformation may be forwarded, denial of the situation may occur, convincing the audience the lie was told to assist or protect them, or the misinformation sender will blame another.

Altruism is not necessarily a part-time attitude, Dawkins (1989) cites many naturally occurring cases where individual or smaller group selflessness operates ensuring the larger group's survival. Therefore, if in nature specific groups survive because of altruism then it can be assumed humans can also obtain and maintain the same positive attitude. If man is higher in understanding than brute beasts of the field, surely the intelligence of man can also attain higher altruistic realms. And if not, why not? 


\section{Evolution of Deception}

Dawkins (1989 pp.7-8) indicates that "if there is just one selfish rebel, prepared to exploit the altruism of the rest, then he, by definition, is more likely than they to survive and have children. Each of these children will tend to inherit his selfish traits. After several generations of this natural selection, the 'altruistic group' will be over-run by selfish individuals". In this short passage, Dawkins (1989) is discussing biological survival, and his argument is indicative of the commonly understood Darwinian perspective of natural selection.

Misinformation follows the same precepts and can be seen to evolve within individuals beginning with a simple deception and then continued partic ipation to ensure the deception persists. The misinformation begets more misinformation. Blackmore (1999 p.76) suggests the propagation of deception requires the actor practicing the deception to "take the other's point of view, to imagine what it would be like to be that other", therefore evolution of misinformation requires an understanding of the recipient's mindset to ensure acceptance of the misinformation.

How does this relate to the young neophyte? The misinformation offered in the early stages of development would rarely be complex and elaborate if offered to an adult audience, though could be considered skillful against peers. The simplistic misinformation may slip past an experienced adult because the mindset of the adult is accustomed to elaborate misinformation stratagems and may overlook the uncomplicated offering therefore allowing the neophyte to indulge in the psychological game. The other alternative is that the adult may have recognized the simplistic maneuver, accepted it, and allowed it to pass. Either way the neophyte is unintentionally or intentionally, invited to continue offering misinformation.

As the neophyte reaches maturity, the trials and errors accumulate knowledge of workable misinformation scenarios, and the knowledge is further increased when other similar mindsets challenge the growing individual. Alternative challenges may include counter-attacks from altruistic individuals with opposing behaviour patterns. These opposing behaviour patterns can either crush or strengthen the neophytes understanding of misinformation stratagems. The same can be said in regards to altruism and the desire for unselfish-based achievements.

Adults employing misinformation strategies in multitudinous settings can indicate the lack of ethical behaviour within each individual. These deliberate and negative actions multiply and propagate creating further situations requiring the foundations to deepen to support the growing misinformation culture. This culture extends into the working life of the adult, who is then required to 'play the game' within organisations to maintain employment and network connections with similar organisations.

\section{Knowledge, Power and Control}

Why utilise misinformation? Foucault (1976) affirms knowledge is power, and the desire for power is based on ego, selfish attitudes, the desire to control others, extinguish words, suppress language, and restrain speech. Knowledge, power and control are part of the greater subjugation process. It creates docile bodies, and is a way of fashioning others to be culturally acceptable and useful to whatever cause is currently in fashion by the group currently in power. In addressing the issue of power, Foucault (1975, 1976) points out that the various forms of power feed the soul or ego, arousing addictive cravings. The historical fall of many great empires occurred when the enigmatic leadership of those empires succumbed to the addictiveness of power and control. The desire to control escalates to the point of egomania giving rise to selective hearing and the fall of that empire becomes inevitable. (See Figure 1.) 


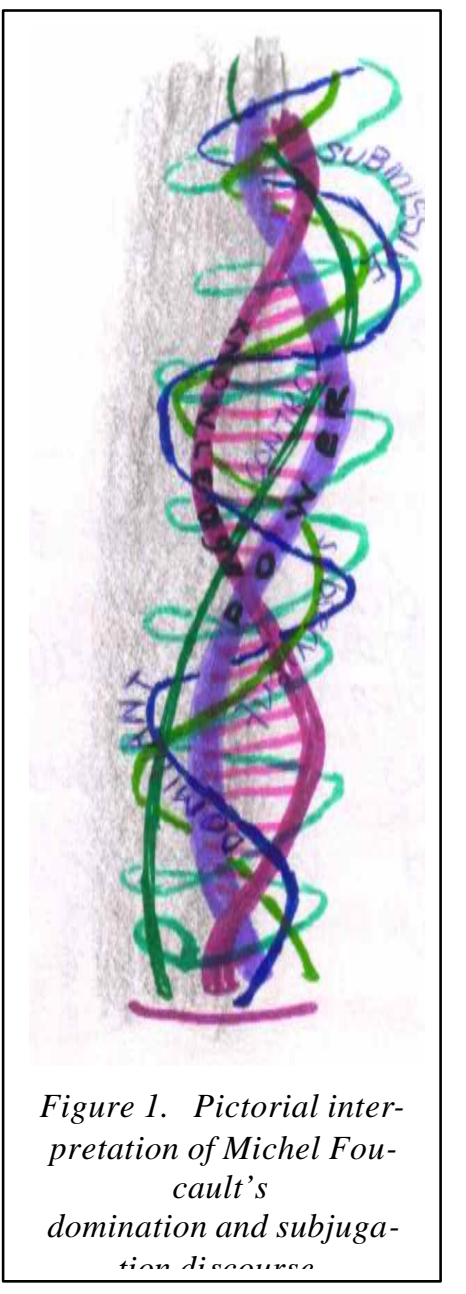

\section{Ego and Selfish Attitudes}

Selfish attitudes operate on three levels: individual, organisational, and national or cultural. Selfishness can stem from fear and a longing to control the surrounding environment and unfortunately, many resort to misinformation to subjugate others in that environment. Niccolo Machiavelli was adviser to Italian princes and his instructions to ensure success and domination included outwitting others by deception, scheming, forming and breaking alliances (Blackmore, 1999). This attitude may initially seem victorious, and the sweetness of success intoxicating, but negativity breeds negativity creating a de-evolutionary cycle of lies and hidden agendas.

Misinformation usage involves an understanding of basic human traits. Selfishness can also originate from self-preservation and is one of humankind's internalised foundations that can be manipulated by misinformation tactics. This self-preservation requires control and power over others to ensure survival, and knowledge is one of the engendering supportive elements. Therefore, misinformation can be interpreted as a method of selfprotection and can be viewed as part of the broader evolutionary cycle. Knowledge manipulates information to ensure domination is effective but from an evolutionary standpoint, it could also mean annihilation over an extended period of time (Dawkins 1989). It is in the interest of dominating powers to ensure that the information and knowledge they are basing their survival on, is correct.

Dawkins (1989 p.8) maintains self-preservation leads to annihilation of species, and eventually, if the mindset or actions persist, radical destruction of interrelated and symbiotic organisms. In logical conclusion, the longterm consequences of the misinformation evolutionary cycle, which requires increased usage of convincing lies to maintain the deception creating greater complexity, will eventually collapse. The environment built on misinformation collapses but within that collapse, a balanced outlook eventuates. Teilhard (cited in Beer 1975 p.18) supports this statement when he describes a continual process of evolution through "complexification" until a future point of convergence emerges. (See Figure 2)

To understand the impact of misinformation, the sender is required to understand the channels power takes, the discourse it permeates to reach individuals, how it gives access to desire, and how it penetrates and controls pleasure therefore misinformation nourishes power. Foucault (1976 p.12) states that the foundations of control are "discursive produc tion, (which also administers silences), the production of power (also functions as prohibition), the propagation of knowledge (often cause mistaken beliefs or systematic misconceptions to circulate)". Foucault continues the argument stating that the central repressive mechanism requires defences, censorship, and denials to be effective.

The effectiveness or success of misinformation relies on the silence of all actors, whether those actors actively cooperate or cooperate from ignorance. Each stance permits misinformation to function on various levels.

\section{Cybernetic Perspective}

Beer $(1974,1975)$ reveals organisations are one of the tools humanity has created to deal with complexity and Foucault $(1961,1975)$ states that organisations are a tool of repression and control, and this repressive dominating system is practiced to maintain routine and compliance. This compliance is encour- 
aged using misinformation tactics and the complexity of society and orga nisational systems have created problems for leadership because, as Beer (1974 p.12-17) suggests, control is required to maintain stability. However, control lessens variety and Ashby's Law of Requisite Variety, which Wiener (1961 p.91 97) and Beer (1974 p.21-34) discuss in detail, explains that variety absorbs variety bring eventual stability using a number of variety attenuators. Long-term stability requires effective and efficient ethical attitudes and managing each attenuator to expose problems, such as those used in effective Quality Management or Best Practice - knowledge management systems. Therefore it is impractical for misinformation to be part of an ethical and stable social or organisational system.

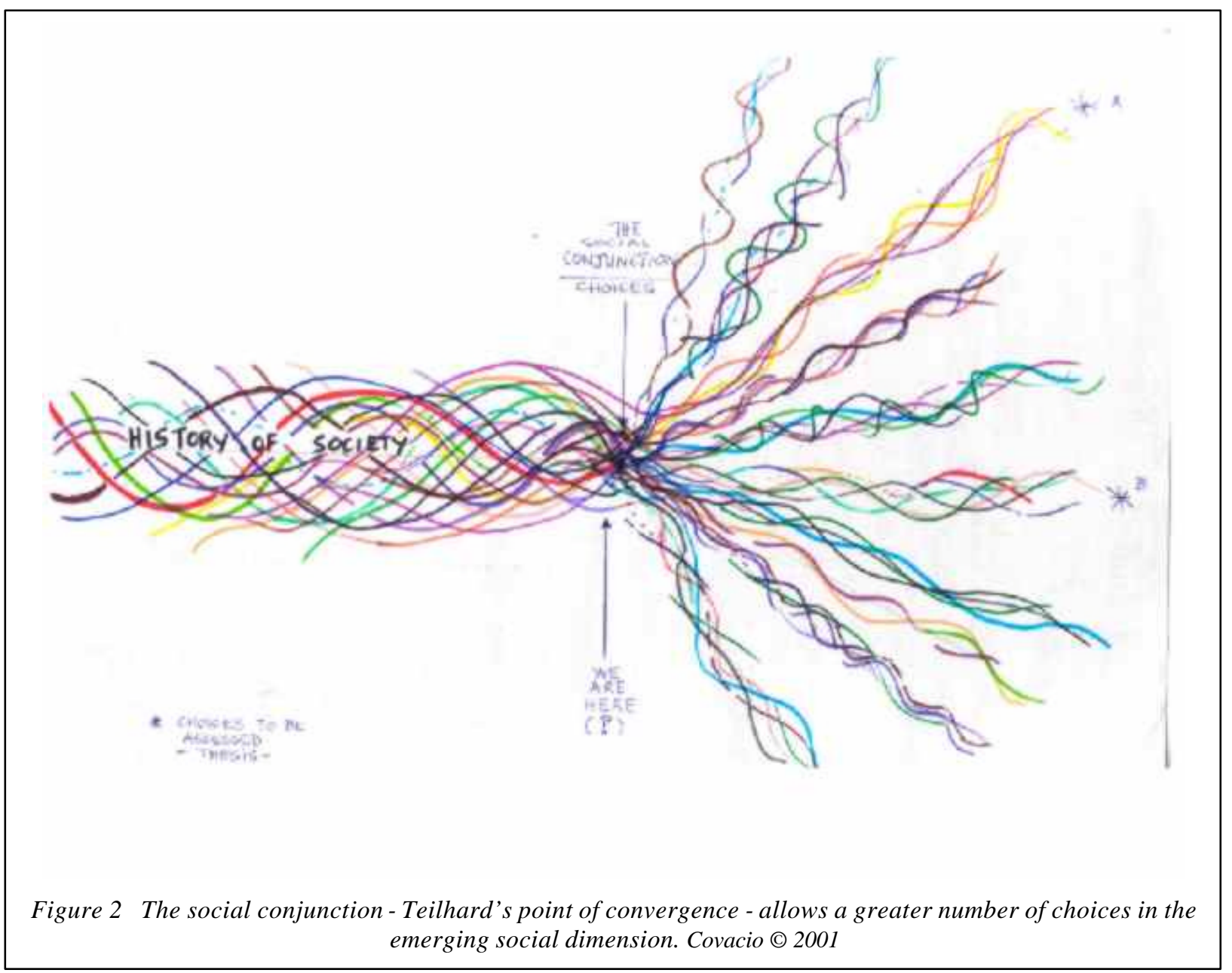

There is an expectation that government, businesses, or other organisations will give a truthful account of their dealings. This is not currently happening on a large scale, if at all, and requires those domains to be challenged to encourage change. A call for these changes requires the current leadership teams to practice ethical standards, and this can only occur if the individual within the team, organisation, or go vernment changes their mindset: honesty begins at a personal level. Kotler, Armstrong, Brown, and Adam (1998) support this statement when they explain that the microenvironment affects the macroenvironment and visa versa. The following illustration illuminates this marketing example. The ethical individual (micro) affects the organisation (macro), this newly affected organisation (micro) affects other organisations they deal with (macro), creating ever widening altruistic and ethical boundaries likened to a Russian doll. The positive influence becomes a powerful networking tool and widespread cooperation built on trust can flourish, toppling the negative influences and greed mentality that pervades current organisational behaviour. 
Organisations based on misinformation will eventually realize that misinformation maintenance is time consuming and resource depleting. To maintain order of the numerous deceptions, a supporting structure is required which necessitates some form of record keeping. Record keeping is control of information and knowledge, and is a structure that supports organisational systems and knowledge management, which Foucault (1975) describe as repressive regimes. Data records are susceptible to unauthorised accessed and present a security risk unless access is strictly controlled, which further depletes resources and profit (Maher, 2002). The current technological filing system seems an effective method of record keeping but there are consequences when relying on technology. Technological failure or software system crashes can deny access at inopportune moments, there is a continual upgrading of computer systems to maintain market domination, new software is required to protect the data in the computer system, and staff training is conducted to maintain the system. These costly repercussions increase pressure and stress on all actors.

The misinformation to security ratio is proportional. The more misinformation utilised, the more security conscious the organisation is prone to be, and one of the reasons why hackers and viruses have come to the fore. Curiosity regarding other people's affairs begins to surface. How did they achieve success? Was it legal or illegal? Who were the instigators? What was the deal? If they held secret meetings; why? The situation tantalizes the imagination and becomes attractive to the investigative mind.

If secrecy and misinformation were not utilised, would it be necessary to employ such battle stratagems? Would society consider the situation dull and boring if altruism reigned? The current systems rely on competition to exist. Could our society operate without competition? What would be the structure of that society? Could we excel to virtuous heights in all areas of society, from science to spirituality if altruism was a permanent human characteristic? This is the utopia often discussed in mythology and poetic literature, and it is an enchanting and bewitching goal, frustratingly beyond our reach; or is it? According to Darwinian principles, it is a possibility. The accumulation of like-mindedness is Teilhard's point of convergence, the moment of cognitive critical mass allowing greater choice within the emerging social order.

\section{Truth Eventually Revealed}

Beer (1974, 1975), Bogard (1996), Foucault (1961, 1975, 1976), Giddens (1993), and Wiener's (1961) arguments and themes clearly indicate the current system is in collapse. Negativity is part of the reason for collapse, and misinformation is part of the negativity. Misinformation can remain veiled if all actors cooperate in silence, and cooperative silence of the perpetration relies on trust; a contrast of character in relation to the foundational characteristics of misinformation. Who can trust others who rely on misinformation for social and political advancement?

The suppression of truth requires control of those involved in the misinformation conception and distribution, and a number of psychological and physical ploys may be implemented. According to Foucault (1975), Giddens (1993), and Millet (1994), these control tactics include fear to try and unsettle the principle altruistic foundations. An individual who does not succumb to initial low-key psychological tactics by controlling factions may find the dominating group targets them. The individual's is labeled 'deviant' and Giddens (1993) discourse, among many others, describes the various methods used to discourage deviant behaviour. The tactics most often incorporated include; verbal threats, actual physical violence toward an individual or loved ones, isolation or ostracism, transfer to another less appealing employment situation, and threats or detrimental changes to financial security. If these tactics do not encourage cooperative silence, the possible physical elimination of the individual could ensue. Power and control is a strong psychological drive and those practicing unethical behaviour will often find altruistic behaviour threatening. The psychological drive to survive is also part of the threatened individual's perspective, and increased threats and intimidation can encourage the threatened individual to retaliate by redirecting 
the learned misinformation tactics to counter-attack the source, creating conflict, deflecting power or affecting compliance of other actors.

Over time, the truth may eventually surface, revealing the multifaceted dimension of power and control in countless situations, much to the dismay of the exposed misinformation sources. Examples of misinformation exposure can be found internationally and unfortunately, is becoming increasingly frequent. The unmasking of numerous chief executive officers activities in prominent national and international companies, and whom have damaged the company's reputation and destroyed the livelihood of thousands of employees, is no longer an isolated incident. Other organisational misinformation examples include governments who have sealed information from public access. Denied access and control of documents is a subjugation tactic utilised by officials to ensure control of knowledge.

The adage "if you are not doing anything wrong, you have nothing to hide" is one that is often forced on citizens but is often not currently practiced by many organisations or go vernments. This obvious double standard is unacceptable, especially when citizens are routinely scrutinised by various bureaucratic methods. The continual surveillance indicates or assumes guilt, creating a society that is required to continually prove their innocence rather than believing citizens are "innocent until proven guilty". This psychological attack indicates a lack of trust by governments and organisations of citizens and employees. Why has this attitude become prevalent? Is it because misinformation has become a tool to gain dominance over competitors? The lack of morals or ethics, on either a personal or an organisational level, by individuals and in many government departments and organisations, is unprecedented. The news broadcasts are evidence of this widespread phenomenon. Millet (1994) likens this type of secretive and controlling behaviour to totalitarian jurisdiction and this behaviour is becoming increasingly active in socalled democratic societies.

The repeated use of the same psychological tactic, such as the use of misinformation to deceive an audience, especially when the true situation is later revealed, lessens the effectiveness and usefulness of the tactic. It is possible to deceive a group of people for a period, but not everyone will succumb to the ploy. When the misinformation is exposed, it educates the audience of the sources' modus operandi or tactical pattern. When the tactical pattern is unmasked, it becomes ineffectual for a period, and enlightenment requires the misinformation source to deepen the deception for effectiveness. The modus operandi now becomes included within the deception, and the misinformation and the modus operandi mutate. One of the more common mutation tactics includes creating confusion by changing the 'rules of the game' while the game is played. Those misinformation recipients aware of the tactics gain greater knowledge and are able to strengthen their psychological defences; a clear example of survival of the fittest.

\section{Conclusion}

Cybernetics is the management of organisations, and organisations are groupings of similar mindsets and behaviour patterns. If cybernetics is viewed from a biological perspective, it is possible to envisage organisations as a species - a collection of like-minds, and each organisation deals with similar minded organisations, these are the symbiotic relationships. As a species, organisations need to survive, and this survival requires organisations to be aware of opposing forces and entities. This pattern for survival is based on evolutionary principles but the issue organisations currently face is the high utilization of misinformation, and within this discourse misinformation is established as a negative behaviour pattern. If organisations are a grouping of like-minds; a founding set of values attracting others with similar values, and there is currently a high level of misinformation in cybernetics, it follows that negativity attracts negativity, therefore the proverb 'you reap what you sow' is justifiably quoted.

Kate Millet (1994) and Anthony Giddens (1993) indicate numerous scenarios where misinformation is utilised to control people thereby control civilization. Dawkins (1989), and Beer $(1974,1975)$ suggest repeated, dominating behaviour patterns will lead to system collapse because an over-abundance of one 
type of entity creates an unstable environment. This evolutionary principle therefore recognizes the annihilation of the individual, species and symbiotic organisms, and if the current system is based on the circulation of high levels of misinformation, how can the current system continue? The adage "if you are not doing anything wrong, you have nothing to hide" acknowledges that misinformation usage is unethical because of the need for secrecy but who can trust others who depend on misinformation for promotion and influence? In addition, if the cybernetic relationship is not based on trust, the individuals or organisation must cooperate in fearful silence to remain part of the organisation, and to ensure loyalty and cooperation, domination and subjugation stratagems are required for success.

Scientific investigative methods and high technology can be utilised to hinder or disseminate information, and surveillance can be easily employed via current and appropriate telecommunication channels. These advancements are advantageous in capturing deviant individuals, those unwilling to succumb to general consensus, nevertheless, there is a warning in this statement to those in official positions. The cost of technology is continually decreasing and private individuals are accumulating knowledge to utilise scientific advancements to detect and expose liars. The tide is beginning to turn.

Beer (1974, 1975), Bogard (1996) and Heylighen (nd), reiterate the fact that organisations or systems are becoming unstable, and collapse seems inevitable. By taking a pro-active approach to this situation, an opportunity exists to change individual operational strategies, effecting other individuals and organis ations. Therefore, if the system of negativity is going to collapse, the key to survival requires disciplined altruistic and honest individuals to cooperate with like-minded individuals and the ensuing ethical behaviour will ensure survival of the fittest.

\section{References}

Beer, Stafford. (1974). Designing freedom. John Wiley and Sons, London.

Beer, Stafford. (1975). Platform for change. John Wiley and Sons, London.

Blackmore, Susan. (1999). The meme machine. Oxford University Press, Oxford.

Bogard, William. (1996). The simulation of surveillance: hypercontrol in telematic societies. Cambridge University Press, Great Britain.

Darwin, Charles. (1958). The origin of species by means of natural selection or the preservation of favoured races in the struggle for life. Mentor Books, New York. (Original work published 1859).

Dawkins, Richard. (1976). The selfish gene. Oxford University Press, Oxford.

Foucault, Michel. (1961). Madness and civilisation: A history of insanity in the age of reason. Translated by Richard Howard. Routledge, London. (Reprinted version: 2001).

Foucault, Michel. (1975). Discipline and punish: The birth of the prison. Translated by Alan Sheridan. Penguin Books, London. (Reprinted version: 1991).

Foucault, Michel. (1976). The history of sexuality: Volume 1 - The will to knowledge. Translated by Robert Hurley. Penguin Books, London. (Reprinted version: 1998).

Giddens, Anthony. (1993). Sociology. $2^{\text {nd }}$ Ed. TJ Press Ltd, Great Britain.

Heylighen Francis. (n.d.). Evolution, selfishness and cooperation. Retrieved 20 June, 2001 from fttp://ftp.vub.ac.be/pub/projects/Principia Cybernetica/Papers Heylighen/Memes\&Cooperation.txt

Maher, William. (2002). Hacking: The big bucks industry. APC, 280:58-64.

Millett, Kate. (1994). The politics of cruelty: an essay on the literature of political imprisonment. Penguin Books, England.

Sandow-Quirk, Mary. (2002). A failure of intelligence. Prometheus, 20(2): 131-142.

Wiener, Norbert. (1961). Cybernetics: or the control and communication in the animal and the machine. $\left(2^{\text {nd }}\right.$ ed.). The MIT Press, Cambridge, Massachusetts. 